\title{
A MATEMÁTICA NA ENGENHARIA - UM PROJETO VOLTADO PARA A BUSCA DE UM PROBLEMA CONTEXTUALIZADO
}

DOI: 10.37702/2175-957X.COBENGE.2021.3550

Karina Bradaschia Rocha - karina.rocha@maua.br

Instituto Mauá de Tecnologia

Rua Rino Pieralini 126

04017-010 - São Paulo - SP

Eloiza Gomes - eloiza@maua.br

IMT

Rua Manuel Figueiredo Landim 126

04693-130 - São Paulo - SP

Juliana Martins Philot - juliana.philot@maua.br

Instituto Mauá de Tecnologia

Rua Bélgica 719

09210-030 - Santo André - SP

Resumo: As pesquisas relacionadas ao ensino e aprendizagem da Matemática nos cursos de Engenharia têm sido foco de atuação de muitos docentes, especialmente no âmbito do COBENGE. As autoras desse artigo, desde 2018, demonstram interesse e preocupação em oferecer o melhor ensino ao estudante, com objetivo de motivá-lo por meio da utilização de eventos contextualizados. Nesse artigo, apresenta-se a organização de um curso, desenvolvido no âmbito dos Projetos e Atividades Especiais (PAE), que são oferecidos aos estudantes de uma Instituição de Ensino Superior como parte das atividades complementares. O objetivo principal do curso, denominado "Aplicações de Cálculo Vetorial na Engenharia", é oferecer ao estudante a oportunidade de compreender melhor como os conceitos matemáticos dessa área são utilizados nos fenômenos estudados na Engenharia. Por meio de pesquisas, os discentes elencaram problemas e detalharam como a Matemática está inserida em suas soluções. A dinâmica de trabalho com os estudantes propiciou o desenvolvimento/mobilização de algumas competências descritas nas Diretrizes Curriculares Nacionais do Curso de Graduação em Engenharia. 


\section{(C. COBENGE e IV Simpósio Internacional

Palavras-chave: Cálculo Vetorial, DCN, Engenharia, Matemática. 


\title{
A MATEMÁTICA NA ENGENHARIA - UM PROJETO VOLTADO PARA A BUSCA DE UM PROBLEMA CONTEXTUALIZADO
}

\section{INTRODUÇÃO}

Desde 2015 o Instituto Mauá de Tecnologia (IMT), sediado em São Caetano do Sul, oferece a seus alunos a oportunidade de participarem dos Projetos e Atividades Especiais (PAE), cujo objetivo é oferecer ao estudante de qualquer um dos cursos oferecidos pela Instituição - Engenharia, Design e Administração - uma disciplina eletiva aberta, mesclando alunos de diferentes áreas e séries, promovendo o contato dos estudantes com um ambiente de trabalho que oportuniza atividades mais práticas e que é diferente das aulas regulares.

Todas essas atividades oferecidas aos discentes buscam atender o que é preconizado nas Diretrizes Curriculares Nacionais do Curso de Graduação em Engenharia - DCN (BRASIL, 2019). Salientamos principalmente o Art. 6ㅜ, que ressalta que o Projeto Pedagógico do Curso (PPC) contemple atividades de aprendizagem para assegurar 0 desenvolvimento das competências estabelecidas no perfil do egresso. Apontamos em especial os parágrafos:

\begin{abstract}
$\S 2^{\circ}$ Deve-se estimular as atividades que articulem simultaneamente a teoria, a prática e o contexto de aplicação, necessárias para o desenvolvimento das competências, estabelecidas no perfil do egresso, incluindo as ações de extensão e a integração empresa- escola.

$\S 3^{\circ}$ Devem ser incentivados os trabalhos dos discentes, tanto individuais quanto em grupo, sob a efetiva orientação docente.

$\S 4^{\circ}$ Devem ser implementadas, desde o início do curso, as atividades que promovam a integração e a interdisciplinaridade, de modo coerente com o eixo de desenvolvimento curricular, para integrar as dimensões técnicas, científicas, econômicas, sociais, ambientais e éticas (BRASIL, 2019, p.3)
\end{abstract}

Para tanto, os discentes têm livre arbítrio para se inscrever no curso que desejarem e fazem isso dentro do Ambiente Virtual de Aprendizagem (AVA), que é a plataforma OpenLMS. Em uma página específica dentro dessa plataforma, estão disponíveis diversas categorias, como "Capacitação em softwares", "Empreendedorismo", "Finanças", "Materiais", "Maquetes e modelagem", "Robótica e automação", entre outros, e, cada uma delas, oferece uma gama de PAE, que são de responsabilidade de professores da Instituição ou de colaboradores externos com experiência no assunto que será abordado. A participação do estudante nessas atividades computa determinado número de horas de atividades complementares.

As autoras deste artigo estão envolvidas com pesquisas relacionadas ao ensino e aprendizagem da Matemática nos cursos de Engenharia, buscando motivar os estudantes com a utilização de eventos contextualizados, que são, de acordo com Camarena (2013, apud Bianchini et al. 2017, p. 71), "problemas ou projetos que desempenham o papel de entes integradores entre disciplinas matemáticas e não matemáticas, convertendo-se em ferramentas para o trabalho interdisciplinar no ambiente de aprendizagem". O trabalho com problemas contextualizados pode influenciar positivamente a motivação do estudante para compreender conteúdos matemáticos em cursos de Engenharia, uma vez que o engenheiro deve ter "uma forte formação em Matemática, porém em Matemática no contexto da Engenharia" (CAMARENA, 2010, p. 19). Alguns exemplos do trabalho com eventos podem ser encontrados em Gomes et al., 2018a, Gomes et al., 2018b e Gomes et al., 2019. 
A construção de um evento contextualizado, na acepção de Camarena (2013), está inserida na fase epistemológica da Teoria A Matemática no Contexto das Ciências (TMCC), desenvolvida por Patricia Camarena desde 1982. A TMCC surge de reflexões a respeito de como motivar um estudante de um curso de Engenharia a aprender Matemática, como vincular essa ciência com a futura profissão do graduando; como a Matemática pode contribuir com a formação integral do estudante e apoiar o desenvolvimento de competências profissionais (CAMARENA, 2013).

Camarena $(2014,2017)$ preconiza que a situação de ensino e de aprendizagem constituí um sistema complexo que estão presentes: os conteúdos a ensinar; o aluno e o docente e as interações que acontecem entre eles. Essas interações são compostas por cinco fases que interagem entre si, denominadas por: fase curricular, fase didática, fase epistemológica, fase docente e fase cognitiva. É na fase epistemológica que se constrói o evento contextualizado para o ensino de Matemática para cursos, como a Engenharia, que não visam a formação de matemáticos. A contextualização está relacionada à ideia de atrelar os conceitos matemáticos a questões referentes às disciplinas específicas e profissionalizantes que os estudantes se depararão durante a graduação ou a situações que estes enfrentarão em suas futuras vidas profissionais (BIANCHINI et al., 2017).

Enquanto professoras da disciplina de Cálculo Diferencial e Integral II ficou marcante, durante as aulas, a inquietação de alguns alunos ao tentar vincular e entender melhor como os conceitos matemáticos apresentados permeiam os problemas da Engenharia. Essa ansiedade ficou bem evidente em tópicos como integral de linha, teorema de Green, Stokes e Gauss, esse último muito utilizado em problemas mais avançados de eletromagnetismo e dinâmica dos fluidos (SOUZA, 2019). Diante deste cenário resolvemos propor, no início do ano letivo de 2021, um PAE denominado "Aplicações de Cálculo Vetorial na Engenharia", que oferecesse ao estudante a oportunidade de compreender melhor como os conceitos matemáticos são utilizados nos fenômenos estudados na Engenharia. Nesse artigo, apresentaremos a organização didática deste PAE e as primeiras reflexões acerca dos resultados preliminares dos nossos encontros.

\section{ORGANIZAÇÃO DIDÁTICA}

Ao término do período de inscrição, tivemos acesso a quantos e quais alunos participariam da disciplina. Com isso, pudemos efetuar a inscrição manual de cada estudante na página específica criada para o projeto no ambiente AVA. É importante ressaltar que o PAE foi planejado para ser realizado de forma remota utilizando a plataforma Zoom, visto que ainda estamos em um momento delicado da pandemia.

Uma semana antes do início efetivo do curso, enviamos dois formulários que deveriam ser preenchidos e devolvidos previamente. O primeiro deles tinha como intuito conhecer em que série o aluno estava matriculado e sua respectiva habilitação (os alunos ingressantes deveriam preencher qual habilitação pretendem seguir, uma vez que nesta instituição o estudante realiza essa escolha após concluída a 1ํㅡㄹérie).

O segundo formulário era constituído de 80 perguntas que compõem o Questionário Honey-Alonso de Estilos de Aprendizagem (CHAEA), elaborado por Catalina Alonso a partir das ideias de David Kolb e dos estudos de Peter Honey e Alam Mumford ${ }^{1}$. Esse questionário inclui quatro seções com 20 perguntas cada, sendo que cada seção corresponde a um dos quatro grupos de estilos de aprendizagem de Kolb: reflexivo, pragmático, ativo e teórico. O Quadro 1 apresenta as principais características do indivíduo pertencente a cada estilo.

${ }^{1}$ Para maiores esclarecimentos a respeito dos trabalhos dos referidos autores, consultar Barros (2008). 
Quadro 1: Principais características de cada estilo da aprendizagem

\begin{tabular}{|c|l|}
\hline Estilo & \multicolumn{1}{|c|}{ Principais características } \\
\hline Ativo & $\begin{array}{l}\text { Têm disposição a novas experiências, são sociáveis, ficam animados com novas tarefas, } \\
\text { têm uma mente mais aberta e não gostam de grandes prazos. Vivem o aqui e o agora e } \\
\text { sempre gostam de ter dias cheios de atividades, são superativos, entusiasmados. Antes } \\
\text { mesmo de concluir uma atividade já estão pensando na próxima. Resumindo, são: } \\
\text { animadores, improvisadores, descobridores, arrojados e espontâneos. }\end{array}$ \\
\hline Reflexivo & $\begin{array}{l}\text { Gostam de analisar as experiências olhando sobre diferentes aspectos, dando prioridade à } \\
\text { observação antes da ação. Além disso, reúnem informações, analisam esses dados com } \\
\text { prudência antes de se chegar a uma conclusão. Gostam de observar a atuação dos outros } \\
\text { colegas antes da tomada de uma decisão. Resumindo, são: ponderado, consciente, } \\
\text { receptivo, analítico e exaustivo. }\end{array}$ \\
\hline Teórico & $\begin{array}{l}\text { Apreciam as teorias lógicas e complexas, enfocam problemas de forma direta, recorrendo a } \\
\text { um raciocínio lógico. Tendem a ser perfeccionistas e gostam de analisar tudo e sintetizar. } \\
\text { Procuram a racionalidade e a objetividade, sentem-se desconfortáveis com conclusões } \\
\text { subjetivas e com pensamentos laterais ou qualquer aspecto superficial. Resumindo, são: } \\
\text { metódico, lógico, objetivo, crítico e estruturado. }\end{array}$ \\
\hline Pragmático & $\begin{array}{l}\text { Aplicam na prática as suas ideias. Gostam de atuar rapidamente e com segurança na } \\
\text { aplicação de suas ideias e projetos atrativos. Tendem a ser impacientes quando a discussão } \\
\text { não tem fim. Basicamente, são pessoas práticas, que gostam de chegar a conclusões } \\
\text { práticas e de resolver problemas. Resumindo, são: experimentador, prático, direto, eficaz } \\
\text { e realista. }\end{array}$ \\
\hline
\end{tabular}

Fonte: adaptado de Barros (2008)

Analisando as respostas do questionário de estilos de aprendizagem, foi possível separar os inscritos em grupos de cinco estudantes, contemplando todos os estilos em cada grupo e também a área de interesse do estudante, na expectativa de uma maior fluidez no trabalho a ser desenvolvido. O curso foi planejado considerando um total de oito encontros, realizados semanalmente e com 100 minutos cada.

A sequência do trabalho desenvolvido pelos grupos em cada um dos encontros preconiza o trabalho colaborativo. Iniciam com uma pesquisa sobre quais são os principais tópicos abordados no Cálculo Vetorial para que, nos próximos momentos, se debrucem em encontrar problemas da Engenharia em que tais assuntos estão inseridos, que é o objetivo principal desse PAE. O último encontro do curso será reservado para que todos os grupos apresentem sua pesquisa e entreguem um relatório que deverá contemplar seis aspectos: o enunciado do problema, sua resolução, os pré-requisitos e conceitos físicos envolvidos, pré-requisitos e conceitos matemáticos envolvidos, discorrer sobre se o problema pode ser utilizado para explorar alguns conceitos matemáticos e, se sim, dizer quais e como e, por fim, um item opcional onde devem discorrer sobre em quais outras áreas da Engenharia esses conceitos poderiam ser aplicados.

O Quadro 2 apresenta a dinâmica de cada encontro, os objetivos e as competências que, em nossa visão, podem ser desenvolvidas/mobilizadas pelos estudantes no decorrer de cada etapa do PAE, bem como algumas observações que julgamos pertinentes com relação à amplitude das características evidenciadas, seguindo o que está estabelecido no Art. 4ํ das DCN (BRASIL, 2019). 
Quadro 2 - Descrição dos encontros

\begin{tabular}{|c|c|}
\hline \multicolumn{2}{|r|}{ Primeiro encontro } \\
\hline Objetivo & Elencar os principais tópicos contemplados em Cálculo Vetorial. \\
\hline Dinâmica & $\begin{array}{l}\text { - Divisão dos alunos nos grupos previamente distribuídos (que serão fixos durante todo } \\
\text { o curso). } \\
\text { - Cada grupo deverá pesquisar os principais assuntos que fazem parte do que se } \\
\text { entende por Cálculo Vetorial. } \\
\text { - Elaborar e socializar uma apresentação de no máximo cinco minutos, com os tópicos } \\
\text { encontrados em sua pesquisa. }\end{array}$ \\
\hline $\begin{array}{l}\text { Competências } \\
\text { mobilizadas/ } \\
\text { desenvolvidas }\end{array}$ & $\begin{array}{l}\text { V - Comunicar-se eficazmente nas formas escrita, oral e gráfica: } \\
\text { a) ser capaz de expressar-se adequadamente, seja na língua pátria ou em idioma } \\
\text { diferente do Português, inclusive por meio do uso consistente das tecnologias digitais } \\
\text { de informação e comunicação (TDIC), mantendo-se sempre atualizado em termos de } \\
\text { métodos e tecnologias disponíveis. } \\
\text { VI - Trabalhar e liderar com equipes multidisciplinares: } \\
\text { a) ser capaz de interagir com as diferentes culturas, mediante o trabalho em equipes } \\
\text { presenciais ou a distância, de modo que facilite a construção coletiva; } \\
\text { b) atuar de forma colaborativa, ética e profissional em equipes multidisciplinares, tanto } \\
\text { localmente quanto em rede. }\end{array}$ \\
\hline Observações & $\begin{array}{l}\text { VI (a), o aluno não necessariamente interage com diferentes culturas, mas sim com } \\
\text { colegas de outras habilitações e séries diferentes da sua. }\end{array}$ \\
\hline \multicolumn{2}{|r|}{ Segundo encontro } \\
\hline Objetivo & $\begin{array}{l}\text { Elencar, dentro dos textos previamente selecionados pelas professoras, os tópicos que } \\
\text { acharem mais pertinentes para seus estudos. }\end{array}$ \\
\hline Dinâmica & $\begin{array}{l}\text { - Cada grupo deverá pesquisar, dentro dos textos apresentados, os tópicos que } \\
\text { acharem mais pertinentes aos seus estudos e à busca pelo problema contextualizado. } \\
\text { - Elaborar e enviar um arquivo texto com os tópicos encontrados em sua pesquisa. }\end{array}$ \\
\hline $\begin{array}{l}\text { Competências } \\
\text { mobilizadas/ } \\
\text { desenvolvidas }\end{array}$ & $\begin{array}{l}\text { Além dos incisos } \mathrm{V} \text { e } \mathrm{VI} \text { apontados no primeiro encontro, também se cita: } \\
\text { II - Analisar e compreender os fenômenos físicos e químicos por meio de modelos } \\
\text { simbólicos, físicos e outros, verificados e validados por experimentação: } \\
\text { a) ser capaz de modelar os fenômenos, os sistemas físicos e químicos, utilizando as } \\
\text { ferramentas matemáticas, estatísticas, computacionais e de simulação, entre outras; } \\
\text { d) verificar e validar os modelos por meio de técnicas adequadas. }\end{array}$ \\
\hline Observações & $\begin{array}{l}\text { II (a), os alunos não irão analisar necessariamente eventos físicos ou químicos, mas } \\
\text { utilizarão as ferramentas matemáticas para entender a solução de um problema ou a } \\
\text { modelagem de um fenômeno descrito em determinada situação. }\end{array}$ \\
\hline \multicolumn{2}{|r|}{ Terceiro encontro } \\
\hline Objetivo & $\begin{array}{l}\text { Apresentar o enunciado de pelo } \mathrm{r} \\
\text { Vetorial presentes e apontar em }\end{array}$ \\
\hline Dinâmica & $\begin{array}{l}\text { - Em posse do enunciado do problema encontrado, identificar os tópicos de Matemática } \\
\text { e/ou Física presentes e explicitar em que área da Engenharia está contemplado. } \\
\text { - Definir em quais assuntos têm conhecimento e qual precisarão estudar. } \\
\text { - Envio de um arquivo com todos os tópicos mencionados anteriormente. }\end{array}$ \\
\hline $\begin{array}{l}\text { Competências } \\
\text { mobilizadas/ } \\
\text { desenvolvidas }\end{array}$ & $\begin{array}{l}\text { Além dos incisos II, V e VI mencionados anteriormente, também se cita: } \\
\text { VIII - Aprender de forma autônoma e lidar com situações e contextos complexos, } \\
\text { atualizando-se em relação aos avanços da ciência, da tecnologia e aos desafios da } \\
\text { inovação: } \\
\text { a) ser capaz de assumir atitude investigativa e autônoma, com vistas à aprendizagem } \\
\text { contínua, à produção de novos conhecimentos e ao desenvolvimento de novas } \\
\text { tecnologias; } \\
\text { b) aprender a aprender. }\end{array}$ \\
\hline Obs & $\begin{array}{l}\text { VIII (a), o alvo do PAE não é o desenvolvimento de novas tecnologias, mas um dos } \\
\text { grandes objetivos é que o discente assuma atitude investigativa e autônoma. }\end{array}$ \\
\hline
\end{tabular}




\begin{tabular}{|c|c|}
\hline \multicolumn{2}{|r|}{ Quarto encontro } \\
\hline Objetivo & Iniciar a elaboração do relatório final. \\
\hline Dinâmica & $\begin{array}{l}\text { - Auxílio aos grupos, principalmente os formados por alunos de } 1^{\circ} \text { e } 2^{\circ} \text { ano, explicando } \\
\text { os conceitos Matemáticos envolvidos no problema escolhido. } \\
\text { - Início do preenchimento do template do relatório final. }\end{array}$ \\
\hline $\begin{array}{l}\text { Competências } \\
\text { mobilizadas/ } \\
\text { desenvolvidas }\end{array}$ & Incisos II, V, VI e VIII mencionados nos encontros anteriores. \\
\hline Observações & Valem as apontadas nos encontros anteriores. \\
\hline \multicolumn{2}{|r|}{ Quinto encontro } \\
\hline Objetivo & $\begin{array}{l}\text { Especificar e compreender os conceitos não matemáticos envolvidos no problema } \\
\text { escolhido e dar continuidade ao preenchimento do relatório final. }\end{array}$ \\
\hline Dinâmica & $\begin{array}{l}\text { - Possível contato com professores de disciplinas específicas para que eles expliquem, } \\
\text { se necessário, algum conceito particular. } \\
\text { - Continuar o preenchimento do relatório final. }\end{array}$ \\
\hline $\begin{array}{l}\text { Competências } \\
\text { mobilizadas/ } \\
\text { desenvolvidas }\end{array}$ & Incisos II, V, VI e VIII mencionados nos encontros anteriores \\
\hline Observações & Valem as apontadas nos encontros anteriores. \\
\hline \multicolumn{2}{|r|}{ Sexto e sétimo encontros } \\
\hline Objetivo & Completar o relatório e preparar a apresentação final. \\
\hline Dinâmica & $\begin{array}{l}\text { - Auxílio aos alunos na finalização do relatório. } \\
\text { - Iniciar a elaboração das apresentações. }\end{array}$ \\
\hline $\begin{array}{l}\text { Competências } \\
\text { mobilizadas/ } \\
\text { desenvolvidas }\end{array}$ & Incisos V e VI mencionados no primeiro encontro. \\
\hline Observações & Valem as citadas no primeiro encontro. \\
\hline \multicolumn{2}{|r|}{ Oitavo encontro } \\
\hline Objetivo & Apresentação final dos grupos e fechamento do curso \\
\hline Dinâmica & $\begin{array}{l}\text { - Envio dos relatórios finais. } \\
\text { - Apresentações: cada grupo terá } 15 \text { minutos para apresentar seguidos de } 10 \text { minutos } \\
\text { de arguição. }\end{array}$ \\
\hline $\begin{array}{l}\text { Competências } \\
\text { mobilizadas/ } \\
\text { desenvolvidas }\end{array}$ & VI mencionados no primeiro encontro. \\
\hline Observações & adas no primeiro encontro. \\
\hline
\end{tabular}

Fonte: As autoras.

Salientamos que este PAE está em andamento e até o momento foram realizados cinco encontros. Na próxima seção apontamos alguns resultados iniciais e também apresentamos um dos problemas explorado por uma das equipes.

\section{RESULTADOS PRELIMINARES}

O PAE "Aplicações de Cálculo Vetorial na Engenharia" proposto pelas autoras, teve 30 alunos inscritos, mas o curso se estabeleceu com 23 alunos, sendo nove da 1a série, onde dois possuem intenção de cursar Engenharia de Produção (PM), um Química (QM), outros dois Mecânica (MC) e quatro Controle e Automação (CA), Computação (CM), Elétrica (EL) ou Eletrônica (ET); oito discentes da $2^{\text {a }}$ série, sendo que dois estão cursando $\mathrm{PM}$, três QM, um MC, um CA e um CM; quatro da $3^{\text {a }}$ série, cursando apenas $\mathrm{MC}$ e dois da 4a série, cursando um Engenharia Civil (CV) e outro MC, dados esses que foram compilados e estão indicados nas Figuras 1 e 2. 
Figura 1 - Série que os alunos estão cursando

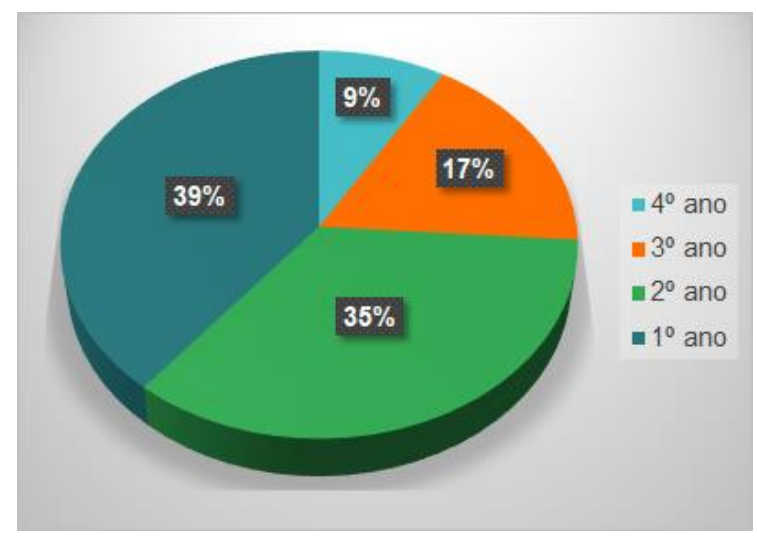

Fonte: As autoras.
Figura 2 - Cursos de intenção ou atuação do aluno

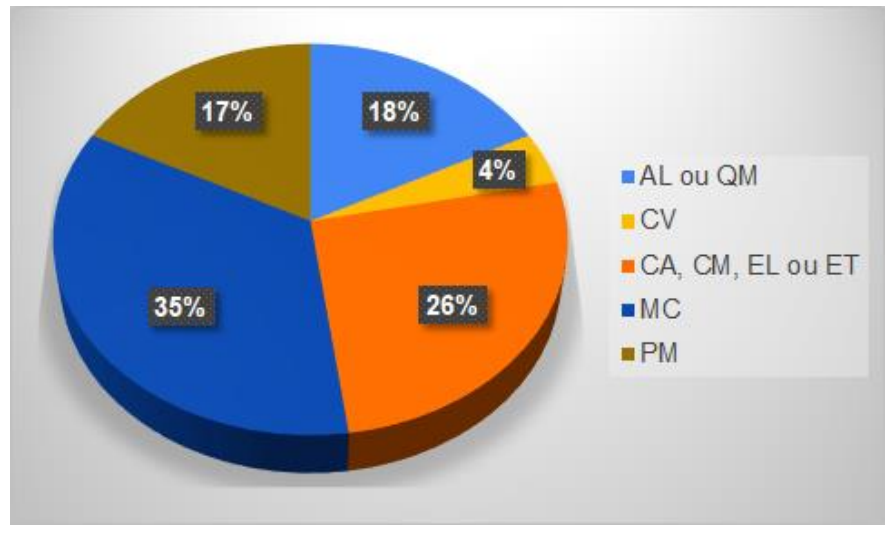

Fonte: As autoras.

A ideia inicial era separá-los em quatro grupos, de acordo com suas áreas de interesse e seguindo os estilos de aprendizagem, como mencionado anteriormente. Porém, a partir do primeiro formulário enviado e como pode ser visto na Figura 1, notamos que mais de $30 \%$ dos participantes estão cursando a $1^{\underline{a}}$ série e muitos conceitos básicos ainda serão desenvolvidos no decorrer do ano letivo. Dessa forma, decidimos dispor os estudantes em grupos mesclados (juntando alunos de $1^{\circ}$ e $2^{\circ}$ ano e de $3^{\circ}$ e $4^{\circ}$ ano) pensando que, além do nosso auxílio, os alunos também podem compartilhar seus conhecimentos.

Os encontros realizados até o momento transcorreram como o previsto, salvo o grupo formado por integrantes da $1^{\underline{a}}$ e $2^{\underline{a}}$ série, que apresentou dificuldade principalmente na pesquisa que deveriam realizar no $3^{\circ}$ encontro e, consequentemente, não cumpriram o que foi proposto dentro do horário previsto. Um dos motivos que corroborou para este fato foi um integrante em particular, que desviava do objetivo do encontro, o que gerou certo desconforto entre os demais integrantes. Sendo assim, nos reunimos com o grupo em um horário extraclasse e propusemos que eles pesquisassem um problema dentro de uma área específica da Física, onde certamente encontrariam os conteúdos de Cálculo Vetorial.

Por outro lado, analisando o que foi enviado pelos três outros grupos, percebeu-se que conseguiram de fato definir uma área de interesse e até mesmo encontrar, dentro de áreas específicas da Engenharia, problemas que utilizassem algum assunto abordado em Cálculo Vetorial no desenvolvimento de sua solução. Como exemplo, podemos citar o problema apresentado por um dos grupos, que estuda a determinação do trabalho realizado para que um pistão se mova, solução essa que se dá por uma integral de linha de campo vetorial. Por mais que tivéssemos indicado alguns textos auxiliares, este grupo em especial desenvolveu seu trabalho com base no artigo de Muniz e Souza, 2019, publicado na Revista de Matemática da UFOP, que se depararam em suas pesquisas. Nesse trabalho os alunos descrevem o funcionamento de um motor de quatro cilindros de combustão interna (Figura $3)$. 
Figura 3 - Motor de quatro cilindros

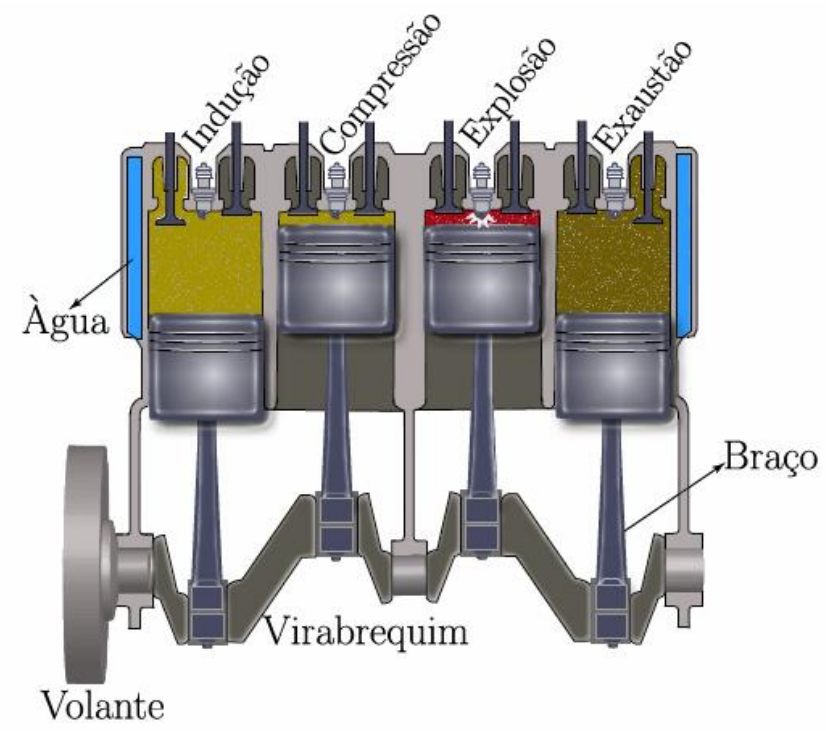

Fonte: adaptado de Muniz e Souza (2019, p.88).

O objetivo dos estudantes é mostrar que o trabalho realizado por um pistão durante um ciclo pode ser determinado pela integral de linha indicada na Equação 1.

$$
\tau=\int_{C} P d V
$$

Depois, completam seus estudos mostrando que é possível calcular o trabalho utilizando o Teorema de Green por meio da subtração das áreas das regiões $D_{1}$ e $D_{2}$, indicadas, respectivamente, pelas cores azul e vermelha na Figura 4. A curva que delimita as regiões ilustra como a pressão $P$ e o volume $V$ variam em um ciclo do motor de quatro cilindros.

Figura 4 - Regiões $D_{1}$ e $D_{2}$

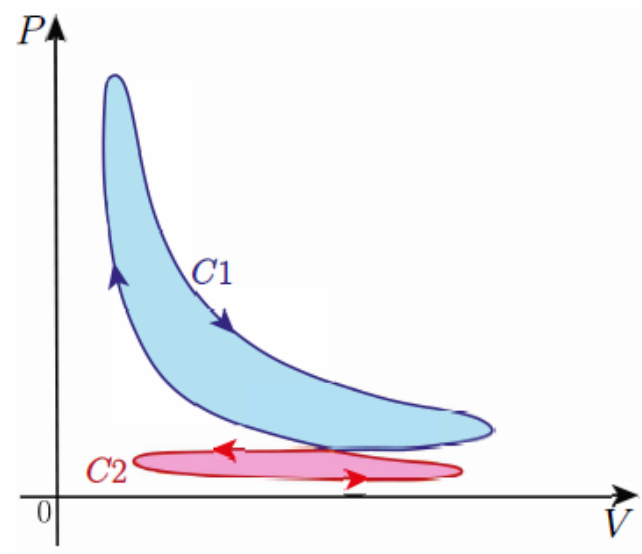

Fonte: adaptado de Muniz e Souza (2019, p.91).

Nos demais grupos, também percebemos que as soluções exploradas se dão, direta ou indiretamente, por uma integral de linha, pois dois grupos estão trabalhando com problemas que empregam conceitos de fluxo e o outro aborda campo magnético. Nesse 
sentido, notamos a importância de se estudar, num curso de Cálculo Diferencial e Integral II, tópicos relacionados à integral de linha, mas sempre buscando a contextualização desse assunto.

\section{CONSIDERAÇÕES FINAIS}

A motivação das autoras para preparar o PAE "Aplicações de Cálculo Vetorial na Engenharia" surgiu da conversa informal com alguns estudantes que cursavam a disciplina Cálculo Diferencial e Integral II, principalmente quando estávamos discutindo as integrais de linha e os teoremas de Green, Stokes e Gauss, pois essas teorias se mostram presentes de maneira indireta nos assuntos que estavam sendo discutidos nas disciplinas específicas cursadas. Percebemos que alguns desses discentes queriam saber além do que era apresentado por seus professores no que diz respeito à modelagem matemática que estavam estudando.

Quando resolvemos apresentar esse PAE, esperávamos que o interesse estivesse principalmente nos alunos dos anos finais do curso de Engenharia, mas constatamos que $39 \%$ de todos os inscritos eram estudantes da $1^{\text {a }}$ série; embora nem todos seguiram o curso até o momento, conjecturamos que existe espaço e alunos interessados em entender com mais profundidade os conceitos matemáticos existentes por trás das teorias abordadas em outras disciplinas, ou, em outras palavras, como a Matemática embasa a solução de problemas da Engenharia.

Nos encontros já realizados, notamos que, mesmo com um modelo de trabalho remoto, os alunos se engajaram em realizar pesquisas na busca por problemas da Engenharia que utilizassem, no desenvolvimento de sua solução, algum assunto abordado no Cálculo Vetorial. Mesmo que o PAE ainda não tenha sido concluído, constatamos o quanto uma atividade nos moldes apresentados neste artigo, pode desenvolver e/ou mobilizar competências importantes para a carreira de um futuro engenheiro. Dentre essas, podemos citar: a comunicação eficaz nas formas escrita, oral e gráfica; o trabalho em equipe; a compreensão de fenômenos físicos e químicos por meio de modelos simbólicos, físicos e outros; aprender de forma autônoma e lidar com situações e contextos complexos.

\section{Agradecimentos}

Agradecemos ao Instituto Mauá de Tecnologia pela oportunidade de oferecer esse projeto, que contribui não só para o desenvolvimento dos alunos como para o nosso próprio.

\section{REFERÊNCIAS}

BARROS, D. M. V. A Teoria dos Estilos de Aprendizagem: convergência com as tecnologias digitais. Revista SER: Saber, Educação e Reflexão, v.1, n.2, p. 14-28, Jul. - Dez. 2008.

BIANCHINI, B. L. et al. Competências matemáticas: perspectivas da SEFI e da MCC. Educação Matemática Pesquisa, São Paulo, v.19, n.1, p. 49-79, 2017. DOI: http://dx.doi.org/10.23925/1983-3156.2017v19i1p49-79.

BRASIL.: Resolução CNE/CES n. 2/2019, de 23 de abril de 2019. Diretrizes Curriculares Nacionais do Curso de Graduação em Engenharia. https://bityli.com/1pxvh (2019). Acesso em: 20 de fevereiro de 2021. 
CAMARENA, P. A treinta años de la teoría educativa "Matemática en el Contexto de las Ciencias”. Revista Innovación Educativa, Vol. 13, No. 62, pp. 17-44 (2013).

CAMARENA, P. La matemática social en el desarrollo integral del alumno. Revista Innovación Educativa, v. 14, n. 65, p. 143-149, maio/ago. 2014.

CAMARENA, P. Aportaciones de Investigación al Aprendizaje y Enseñanza de la Matemática en Ingeniería. https://bityli.com/GjeSQ (2010). Acesso em: 02 de julho de 2020.

CAMARENA, P. Didáctica de la matemática en contexto. Educação Matemática Pesquisa, Vol. 19, No. 2, pp. 01-26 (2017) DOI: http://dx.doi.org/10.23925/19833156.2017v19i2p1-26.

GOMES, E.; FABRI, A. V. N.; ROCHA, K. B.; BOLELLI, P. M.; SCALCO, R. Utilização De Eventos Contextualizados Nas Aulas De Vetores E Geometria Analítica - Primeiras Reflexões. 2018a.

GOMES, E.; LIMA, G. L.; BIANCHINI, B. L.; ROCHA, K. B.; BOLELLI, P. M. Análise Dinâmica De Pórticos: Uma Oportunidade Para A Construção De Um Evento Contextualizado Para O Ensino E A Aprendizagem De Álgebra Linear. 2018b.

GOMES, E.; LIMA, G. L.; BIANCHINI, B. L.; ROCHA, K. B.; BOLELLI, P. M. Evento contextualizado: estudo de um problema da Engenharia Civil para o ensino da Matemática. In: XV Conferencia Interamericana de Educación Matemática, 2019, Medellín. Anais do XV Conferencia Interamericana de Educación Matemática. v. 1. p. 1-1., 2019. v. 1. p. 1-10.

MUNIZ, N.; SOUZA, T. O. Aplicações práticas para o ensino e aprendizagem das integrais de linha e superfície. Revista de Matemática da UFOP (2237-8103): v.06 pp:84101. 2019.

SOUZA, F. N. N. Teorema da divergência e aplicações. Universidade Estadual da Paraíba. 59 p. 2019. 


\title{
MATHEMATICS IN ENGINEERING - A PROJECT FOCUSING ON THE SEARCH OF A CONTEXTUALIZED PROBLEM
}

\begin{abstract}
Researches related to teaching and learning of Mathematics in Engineering courses has been the focus of many teachers, especially within COBENGE. The authors of this article, since 2018, have shown interest and concern in offering the best teaching to students, motivating them by using contextualized events. This article presents the organization of a course, developed within the scope of Projects and Special Activities (PAE), which are offered to students at a Higher Education Institution as part of complementary activities. The main objective of the course, called "Vector Calculus Applications in Engineering", is to offer the student an opportunity to understand how mathematical concepts of this area are used in the phenomena studied in Engineering. Through research, students listed problems and detailed how Mathematics is inserted in their solutions. The dynamics of working with students led to the development / mobilization of some competencies described in the National Curriculum Guidelines for the Undergraduate Engineering Course.
\end{abstract}

Keywords: Vector Calculus, DCN, Engineering, Mathematics. 